\title{
Global comparison of professional positioning by pharmacy programs towards prospective students
}

\author{
Kyle John Wilby ${ }^{\mathrm{a}, *}$, Daniel C. Rainkie ${ }^{\mathrm{b}}$ \\ ${ }^{a}$ School of Pharmacy, University of Otago, PO Box 54, Dunedin, 9054, New Zealand \\ ${ }^{\mathrm{b}}$ College of Pharmacy, Qatar University, PO Box, 2713, Doha, Qatar
}

\section{A R T I C L E I N F O}

\section{Keywords:}

Recruitment

Enrolment

Positioning

Admissions

\begin{abstract}
A B S T R A C T
Background: Enrolment of capable prospective students for pharmacy programs is a major priority for the profession. The way in which these students perceive a future career in pharmacy may be dependent on how programs position the profession using recruitment material.

Objectives: Objectives were to determine how top ranked pharmacy programs across 5 countries position the profession to prospective students on website recruitment material and to compare similarities and differences in how programs use speech acts within positioning statements.

Methods: A qualitative, thematic analysis of publicly available online recruitment information extracted from the top 2 ranked English-speaking pharmacy programs (according to 2018 QS rankings) from each of Australia, Canada, New Zealand, United Kingdom, and the United States was completed.

Results: Three positioning themes were identified: Pharmacists as health professionals and medicines experts; Pharmacists evolving role as care providers; and Pharmacist diversity in careers. Programs used questions, statistics, and carefully selected words to engage readers, backup statements with evidence, and market positioning statements to younger generations.

Conclusions: Pharmacy programs position the profession using similar themes but use different strategies to relay positioning messages to prospective students. These findings may have implications for fostering prospective student interest in pharmacy programs.
\end{abstract}

\section{Introduction}

Recruitment for professional pharmacy degrees is becoming highly competitive worldwide. ${ }^{1,2}$ Programs must not only compete with other institutions offering pharmacy qualifications, but also other professional degrees such as medicine, nursing, dentistry, physiotherapy, and other health sciences. ${ }^{1,3}$ Many factors have been identified that appear to influence students' choices to apply specifically for pharmacy. Overwhelmingly, these include 'real-life' previous encounters with the profession and/or encouragement from others such as family and friends. ${ }^{4,5}$ Other avenues such as career days have been reported to be less influential but still may play role. ${ }^{5}$ Little information is known regarding the role of websites and the use of social media on students' application decisions. Given the high competition for attracting quality applicants, effective targeted marketing of programs to prospective students is becoming a major priority and online material/messaging will likely have an increasing role moving forward. It is currently unknown, however, how these messages are presented to prospective students in order to support their application-related decision-making.

One of the essential components of marketing programs is that of positioning. $^{1,6}$ The concept of positioning asserts that established practice, assumptions, and the use of language affect how one perceives an entity (e.g. pharmacists) to be situated with respect to themselves (e.g. prospective student) and within the world itself (e.g. profession, comparisons between schools of pharmacy and other healthcare professions). ${ }^{7}$ Positioning occurs largely through communication, whether it be written, spoken, or projected through images or other audiovisual mechanisms. ${ }^{8,9}$ In the case of pharmacy program recruitment, effective positioning enables prospective students to have a clear image of the program in their minds and allows them to understand how it is similar yet different from other competing programs. ${ }^{1}$ These messages must be tailored to position the program with respect to the specific program features, needs and wants of the target market, and competing alternatives available to target students. Although global pharmacy programs differ in degrees earned, program length, and practice standards, the need to market/position a program is likely an international

\footnotetext{
${ }^{*}$ Corresponding author.

E-mail addresses: kyle.wilby@otago.ac.nz (K.J. Wilby), drainkie@qu.edu.qa (D.C. Rainkie).
} 
trend. $^{10}$

The conversation that transpires between the institution and the prospective student relies on three major components known as the positioning triangle: positioning, speech-acts and an overarching storyline. ${ }^{11}$ Positioning occurs through the use of language by assigning attributes to the individual or group being positioned. The positioning approach to the speech-acts can be either direct or indirect (what is said compared to what is implied). This use of language, the speech-acts portion of the discourse triad, will precisely dictate how one may perceive and understand the positioned entity. ${ }^{11,12}$ In the case of pharmacy student recruitment, effective use of language may provide a clear image of the profession of pharmacy and novel attributes of the program being positioned. ${ }^{1}$ It is possible, however, that language could also position a program in a way that opposes understanding of the societal roles of pharmacists or specific program attributes and makes a program less attractive. ${ }^{13}$ Social positioning theory is linked with social constructionism, which identifies language of having a major role in establishing societal roles. ${ }^{12}$

Ultimately, the prospective student may accept the positioning and speech-acts and apply to a pharmacy program or they may reject it depending on their own past experiences with the profession as part of the overarching storyline. According to Davies and Harre, individuals processing the same interaction may interpret and construct the positioning storyline in different ways. ${ }^{12}$ It is possible, for example, that the use of words or abbreviations common to younger generations may not be understood within the same context by older generations. This triangle is dynamic, with each component able to influence the others. ${ }^{11}$ It can therefore be envisioned that modifications in what programs state on recruitment material (i.e. what they say and do) may directly impact the positioning and associated storyline of being a pharmacy student or pharmacist in their respective context.

Given the increasing importance of recruitment for the pharmacy profession, the rise in use of electronic and social media, and the key role that training programs have in professional promotion, it is important to understand how the role of pharmacists is being positioned to prospective students within online media. The purpose of this study was therefore to explore the concept of professional positioning by pharmacy programs to prospective pharmacy students. The specific research questions that this study aimed to answer were:

1 How do educational institutions position pharmacists to prospective students by pharmacy training programs using online recruitment material?

2 How is the language (i.e. speech acts) used to position pharmacy training programs similar or different between institutions?

\section{Methods}

Study design

This was a qualitative study that used a social constructivist approach to thematically analyze publicly available online recruitment information targeted to prospective undergraduate pharmacy students. ${ }^{14}$ Positioning theory, a social constructionist paradigm, was used as the framework for the study and for analyzing the data (see Data Analysis). ${ }^{11,12}$ This theory was chosen based on the close link with marketing (e.g. recruitment) and the reliance on language (e.g. speech acts). Previous studies have used positioning theory to examine pharmacist roles and scope of practice, and for the analysis of written text obtained from sources such as news media. ${ }^{9,15}$ According to positioning theory and as discussed above, positioning can be indirect or direct. ${ }^{11}$ Investigators approached the data through the lens of positioning theory to identify positioning themes and speech acts that provide valuable information of how pharmacy programs market the profession to prospective students and how a programs' positions and associate speech acts may influence the storylines produced as the third dimension of the positioning triangle.

\section{Reflexivity}

Both investigators were academic staff members at different institutions in two different countries. Both had extensive pharmacy practice experience in hospital and community settings. One investigator is a program administrator for which student recruitment falls under the portfolio (KW). Despite best efforts to analyze data independently and objectively, it is possible that investigators' past experiences may have influenced results by identifying components of material (e.g. word choice) familiar to their own settings. Additionally, both investigators were originally Canadian (although neither were working in Canada at the time of this study), which may have influenced cultural preferences for language and their own perceptions of pharmacy practice. Both investigators have had training in qualitative research methods and have experience leading qualitative research projects. One investigator (KW) completed a $\mathrm{PhD}$ in health professions education that was largely based on qualitative research methods. Investigators followed the relevant sections of the Standards for Reporting Qualitative Research (SRQR) when writing this manuscript. $^{16}$

\section{Data collection and processing}

A total of 10 programs were identified across five English-speaking countries (Australia, Canada, New Zealand, United Kingdom, United States). The two highest ranked English-speaking programs, according to 2018 QS ranking systems (Pharmacology/Pharmacy subject area), for each country were sampled. ${ }^{17}$ This form of sampling was chosen to provide a global perspective by including an equal distribution across countries. As only two programs are available in New Zealand, it was decided to limit the sample to two from each country and to sample the highest two ranked to be consistent across all countries. Sampled institutions could not be from the same province or state in each country and must operate a professional pharmacy training program. The sample was restricted to English-based programs to avoid misinterpretation of language occurring through translation. The selection of countries was purposively selected to ensure broad representation across international settings.

Publicly available data were collected from the websites of these institutions (March 2019). ${ }^{18-27}$ The material extracted was webpage content providing an overview of the profession and program for prospective students and any additional information that described future career opportunities for pharmacists. This information was found on program home pages, 'about us' pages, career opportunity pages, and pages that provided an overview of the curriculum. Pages that were not specific for the program (e.g. faculty bios, research pages, graduate degrees) were not reviewed. All data were extracted with basic formatting by copy and paste of text without any images or other aspects of the website into one word processing document for analysis.

\section{Data Analysis}

A thematic analysis was conducted according to social positioning theory. ${ }^{11,14}$ Both investigators began by independently reviewing the extracted data from one program. Each investigator read the data multiple times to familiarize themselves with the messages of the program. After this familiarization phase, investigators independently coded the data for words, phrases, or segments deemed to contribute to the positioning of the profession to readers. For example, a sentence stating 'pharmacists are medicines experts and work collaboratively with other healthcare professionals' would be coded as 'medicines expert' and 'collaborative'. Coding was completed by hand on hardcopy by highlighting the words, phrases, or segments and assigning a code in the paper margins. After coding the data for one program, investigators 
met to review coding, identify and resolve discrepancies, and to agree on how to label each new and existing code (e.g. 'collaborative' or 'team'). Investigators then repeated the process for a second program's data. Again, investigators met afterward to discuss coding, resolve discrepancies, and agree on labels for any new codes. This process repeated until all data was coded. At this point, codes and associated raw data were entered into a spreadsheet for further analysis. Investigators reviewed this data and combined related codes into broader categories. Investigators then met to generate a preliminary list of positioning themes (e.g. to answer the research question of how programs position the profession using written recruitment material). Once themes were generated, investigators reviewed the raw data for confirming or disconfirming evidence for each theme. Both investigators then agreed upon final positioning themes. Representative quotes were extracted from the data to illustrate themes and support the interpretation of data.

A between case analysis was conducted to investigate how the speech acts used by programs to position the profession were similar or different across programs. Each institution was considered as a separate case for this analysis. ${ }^{28}$ The raw data that was coded for each theme was revisited and compared and contrasted for patterns across cases (programs) to search for similarities and differences in the positioning posture (direct or indirect) and language (i.e. speech acts) used to support each theme. Investigators independently highlighted any speech act (including specific word choice) that programs used within their positioning statements. Investigators then came together to compare results and agree on which speech acts could be considered to support positioning of the program (e.g. enhanced the marketing of the profession to prospective students). Final agreed upon speech acts were compared and contrasted across cases (programs) to search for similarities and differences in how programs used speech acts for positioning.

\section{Results}

The sampling strategy identified the following programs: Monash University (Australia), University of Sydney (Australia), University of Toronto (Canada), University of British Columbia (Canada), University of Otago (New Zealand), University of Auckland (New Zealand), University of Nottingham (UK), University College London (UK), University of California at San Francisco (USA), University of Michigan (USA). The University of California at San Diego was excluded, as it is located in the same state as the higher ranked program (University of California at San Francisco).

The thematic analysis identified three themes related to how pharmacists are positioned towards prospective students across all programs: pharmacists as health professionals and medicines experts; pharmacists' evolving role; and pharmacists' diversity in careers. Despite the presence of these themes across all sampled programs, the speech acts used to describe each theme greatly differed. The positioning themes are described in further detail below and supportive statements are provided in Table 1. Examples of differences in positioning speech acts are provided in Table 2.

\section{Theme 1: Pharmacists as health professionals and medicines experts}

Pharmacists were positioned to be health professionals and medicines experts including perspectives from clinical care and basic sciences. Specific roles related to this theme included preparation and dispensing of medicines, provision of medicines information to patients and other healthcare professionals, and experts in drug design and development. The position as a 'health professional' also included many different functions, including patient care and counselling, the ability to manage diseases and contribute to improving the health of populations, and being skilled in their expertise as part of the healthcare team. The type of positioning used primarily in this theme is direct self-positioning used in defining the roles of the pharmacist, but also direct self- repositioning used to describe the pharmacist's ability to manage diseases and acting as a fundamental part of the healthcare team. This theme also included indirect self-positioning by implying that no other healthcare profession would know more about medications than the pharmacist.

\section{Theme 2: Pharmacists' evolving role}

Pharmacy programs positioned the role of the pharmacist to be evolving and one that is an essential part of the healthcare team. The programs used concepts such as team-based care and collaboration with physicians and other healthcare professionals to highlight this point. There was also a direct focus on new pharmacist services that may attract prospective students seeking advanced scopes of practice. Some of these services included prescribing, vaccine provision, and providing comprehensive medication reviews. This theme was underpinned by descriptions of pharmacists evolving into advanced, or full scopes of practice outside of the traditional dispensing and advising roles. This theme principally employs direct self-repositioning to show that there are new, modern roles and responsibilities of pharmacists outside of the traditional services offered by pharmacists.

\section{Theme 3: Pharmacists' diversity in careers}

Diversity in career opportunities was a central theme to all programs. Despite, at times, still focusing on traditional practice settings such as community and hospital sites, programs positioned the careers for pharmacists to be ever changing and to encompass a wide variety of settings and roles. Specific career opportunities that were commonly positioned included community/retail pharmacy, hospital pharmacy, industrial pharmacy, academia, government and policy roles, research, business ownership, and medical information. The underpinning message to most programs was that the diversity of career opportunities results in high employability. This theme mainly applies direct selfpositioning and direct self-repositioning to describe the career opportunities available to pharmacists after graduation that includes common and uncommon career paths.

\section{Differences in positioning speech acts}

The between case analysis found programs use differences in speech acts to position their programs (Table 2). Specifically, the use of questions to engage in conversations with readers, the use of statistics to provide factual representation, and the choice of words to create interest were used to varying extents across different programs. Programs from the United States were noted to use statistics, while the Canadian schools were noted to use questions. Australian and Canadian programs more commonly used word choices that appeared to be targeted towards newer generations.

\section{Discussion}

This study found that institutions might have a central role through how they position pharmacists to prospective students as medicines experts with evolving roles and diverse career opportunities. Results found that despite positioning within common themes, the way in which positioning statements are made differ across programs. These statements are conveyed to students using different acts of speech, which may directly impact how students conceptualize the profession and the intended outcomes of the degree program.

The center of this discourse is related to the credibility and the authenticity of the statements made by the institutions about pharmacists. According to configuration theory, the credibility and reputation of the institution to local and international prospective students is dependent on core values and ideas, which may be communicated using positioning. ${ }^{29}$ As per to positioning theory, if the statements made on 
Table 1

Identified themes, supporting statements and type of positioning extracted from recruitment websites.

\begin{tabular}{ll}
\hline Theme & Supporting Statements \\
\hline
\end{tabular}

Pharmacists as health professionals and medicines experts

Pharmacists' evolving role

Pharmacists' diversity in careers
Pharmacists are health professionals and experts on medicines. They give information on medicines, drug therapy, and disease management to patients, doctors and other health professionals. (UO)

Pharmacists are among society's most trusted and accessible health care professionals, and they are often the first point of contact for individuals with health concerns. (UBC) Pharmacists are healthcare professionals who are experts in medicines, with a detailed understanding of the scientific basis of therapy. (UCL)

Pharmacists are experts in medicines and how they work, which, combined with their professional skills, opens up a number of career opportunities to them. (UN) Pharmacists are health care professionals which play a pivotal role as medication therapy experts, providing convenient accessible and high quality patient care. (UT) An ageing global population, increasingly complex and personalised medicines, as well as a move towards team-based 'integrated' healthcare mean that the challenges and opportunities facing pharmacists are greater than ever before (UM).

The game is changing.w This is a time of evolution and opportunity for pharmacists and professionals in the field of pharmaceutical sciences.(UBC)

Pharmacists do much more than fill prescriptions - they are an integral part of the healthcare system and have the capacity to directly affect the lives and lifestyles of the people with whom they interact. (US)

The traditional dispensing and advisory role associated with community pharmacy is evolving and pharmacists are playing a greater role in patient care. Some community pharmacists now have prescribing roles and are involved in services such as weightmanagement counselling. (UN)

Pharmacy has a long and remarkable history, but it isn't stuck in the past. Our ageing population makes an increased and changing demand for pharmacists' skills inevitable. The ever growing complexity of medicines will mean that pharmacists will require even higher levels of scientific knowledge. The growth of healthcare teams will mean that increased scientific knowledge will need to be matched by a growth in soft skills like teamwork, communication and problem solving. Whatever the future holds, though, one thing will remain the same: pharmacists will always do the sort of work that changes people's lives for the better. (MU)

An Entry-to-Practice PharmD degree unlocks a wealth of rewarding career paths in the pharmaceutical sciences. It's not just about dispensing prescriptions. Absolutely, you can join one of the most trusted professions in the world as a practising pharmacist, but there's more to a PharmD than that: you can pursue a career in government health policy, open your own business, or continue your studies toward a meaningful career as a researcher. A world of possibility starts here. (UBC)

And if you're not working in a pharmacy itself, you might find that your career takes you to roles in government, industry, research or clinical-trials. (MU)

Graduates will have the necessary skills to pursue licensure to practice pharmacy. With this licensure graduates may choose to pursue many different paths - the UM program is broad enough to offer extensive opportunities that lead to careers in health systems, community pharmacy, pharmaceutical companies, government and other public sector jobs, as well as careers in the academic world. (UM)

Opportunities for pharmacists are constantly growing as the healthcare sector changes to meet the needs of our communities. Some pharmacists are even involved in border control. (UO)

Career paths include community pharmacy, health systems, health policy, research, academia, business, government, industry, ...more. (UCSF)
Type of Positioning

Direct self positioning - medication expert Direct self positioning - medication advisor

Direct self positioning - trusted HCP Direct self positioning - accessibility Direct self positioning - medication expert

Direct self positioning - Medication expert Direct self-repositioning - Opportunities Direct self positioning - Medication expert Direct self positioning - accessibility Direct self positioning - Essential service Direct self repositioning - challenging career

Direct self repositioning -Integrated part of healthcare

Indirect self repositioning - changing roles and responsibilities, innovation

Direct self repositioning - opportunities Direct self repositioning - deemphasis of traditional services

Direct self repositioning -Integrated part of healthcare

Direct self positioning - direct care provider Direct self repositioning - deemphasis of traditional services

Direct self positioning - changing roles and responsibilities

Direct self positioning - direct care provider Direct self repositioning - deemphasis of traditional services

Direct self positioning - changing roles and responsibilities

Direct self positioning - direct care provider Direct self repositioning -Integrated part of healthcare

Direct self-positioning: fulfilling career Direct self-repositioning: deemphasis of traditional services

Direct self-positioning: trusted profession Direct self-repositioning: career opportunities

Direct self-repositioning: career opportunities

Direct self-positioning: diversity of skills Direct self-repositioning: career

opportunities

Indirect self-repositioning: career opportunities

Direct self-repositioning: career opportunities

$\mathrm{UO}=$ University of Otago; UBC=University of British Columbia; UCL= University College London; UM=University of Michigan; US=University of Sydney; $\mathrm{MU}=$ Monash University.

Table 2

Contrasting use of speech acts within program's discursive positioning.

\begin{tabular}{|c|c|c|}
\hline Strategy & Example 1 & Example 2 \\
\hline $\begin{array}{l}\text { Engaging in a conversation using } \\
\text { questions }\end{array}$ & $\begin{array}{l}\text { Do you want your job to have meaning? Are you } \\
\text { passionate about changing people's lives for the } \\
\text { better? (UBC) }\end{array}$ & $\begin{array}{l}\text { Are you looking for an outstanding degree to start your career as a pharmacist? } \\
\text { Wanting to develop your professional knowledge and skills to become a leading } \\
\text { expert in drug discovery and the design of medicines? Taking your research } \\
\text { interests in pharmaceutical sciences to the next level? (UN) }\end{array}$ \\
\hline $\begin{array}{l}\text { Use of statistics as factual } \\
\text { representation }\end{array}$ & $\begin{array}{l}\text { ' } 80 \% \text { of graduates were satisfied with their post- } \\
\text { graduation employment plans' (UM) }\end{array}$ & $\begin{array}{l}\text { Upon graduation, } 65 \% \text { of our students pursue, and are highly competitive for, } \\
\text { postgraduate training or education in the form of residencies, fellowships, or } \\
\text { advanced degrees (UCSF). }\end{array}$ \\
\hline Word choice & 'Medicines superheroes' (MU) & 'Health professionals who are experts in medicines' (UCL) \\
\hline
\end{tabular}

$\mathrm{UBC}=$ University of British Columbia; UN = University of Nottingham; UM = University of Michigan; UCSF = University of California at San Francisco; MU = Monash University; UCL $=$ University College London. 
the institutional website are in conflict with the individual's own experiences (e.g. an individual has never experienced or heard of a pharmacist prescribing medications), then the credibility or authenticity of the statements are questioned and ultimately the discourse will be rejected. ${ }^{11}$ Conversely, if the discourse is relatable to the target individual, it may have a greater chance for acceptance. While this study found overall similarities in the positioning of pharmacists, it is currently unknown how prospective students perceive this positioning. Furthermore, the text and speech acts used to describe these positions differed and may have implications for how prospective students relate to the material provided.

The speech-acts moiety of the positioning triangle focuses on how the positioning statements are relayed to the reader. ${ }^{12}$ Inherently, website text is a unilateral act where it is not possible for a true conversation to occur. However, some institutions used the speech act of asking questions to engage students. This strategy personalizes the information provided and may therefore result in storylines of greater relevance to the prospective student. Other programs used factual representation through the use of statistics to support their claims. This strategy may intend to produce storylines that are more impressive to students. Interestingly, the programs that used this strategy were located primarily in the USA and UK, where students have greater choices of available pharmacy programs. This study also found that the choice of words to describe similar concepts differed between programs. Using words that are active, appealing, and targeted to millennial and postmillennial generations (i.e. 'superheroes') may once again, relate better to the student and result in a more appealing storyline. ${ }^{30}$

The types of positioning used by institutions, direct and indirect, were used to resonate with prospective students and identify those that may want to join the positioned program. The goal of employing different types of positioning is to say "yes, I am what you think, but I am also these" in the hopes that this influences the students storyline and eventual decision. ${ }^{11}$ The majority of the positioning that occurred on institution websites were direct self-positioning and direct self-repositioning. This allows the reader to acknowledge what is common or already known about the profession of the pharmacist (e.g. medication expert, trusted healthcare professional, accessible) but also garner an understanding of what perhaps was not known before (e.g. integrated in the healthcare team, deemphasizing traditional services, changing roles and responsibilities, and the numerous career opportunities). What was not seen in the websites is the positioning of others or by others. Positioning by others would be described as a 3rd party joining the conversation..$^{11}$ This may be a quote from a physician who describes how pharmacists are an integral part of the healthcare team or a patient story of how a pharmacist saved a patient's life by identifying a drugdrug interaction. In the other direction, positioning of others would be institutions in relation to other institutions or pharmacists as compared to other healthcare professionals. The positioning of others and by others provides an additional perspective, a 3rd party to join the conversation, and allows the reader to validate self-repositioning offered by the institution. It could be speculated that this type of positioning may become more common in the future as professions increasingly compete to recruit qualified students.

This study has implications for student recruitment. Programs should review published recruitment material through the lens of positioning theory, in order to understand how their target audience may be interpreting the statements made. More specifically, programs should work towards developing material that is relatable to prospective students and should place effort on determining what speech acts (including word choice) may resonate better with these newer generations. In the era of social media and rapidly changing ways in which people communicate, this information should be frequently reviewed and assessed for relevance and acceptability by target readers. Millennials and post-millennials, for example, are known to prefer short messages embedded with high energy. ${ }^{30}$ Incorporation of these types of positioning speech acts could be speculated to resonate better with this generation but future research is required to confirm.

This study also has implications for future research. First and foremost, prospective student preferences in terms of the speech acts used within recruitment material should be assessed. These could be categorized according to the positioning themes identified in this study. The way in which programs describe pharmacists, roles in practice, and career opportunities, for example, should be assessed against preferences and interest. Studies should also be designed to better understand the role of positioning theory in development of online recruitment material. Eliciting the storylines of how prospective students envision the profession based on the program's positioning and the use of speech acts to convey positioning statements will allow greater understanding of how the positioning triangle may be used strategically to influence student recruitment.

Trustworthiness of the results of this study is supported by the design, methods, and findings. The common positioning themes identified across all programs demonstrates transferability of findings across international settings despite differences in pharmacist roles and responsibilities, program length and degrees earned. Although a limitation of this study is the small sample size, this finding supports the notion that pharmacy programs around the world are positioning the profession in similar ways. Trustworthiness is also supported by independent review of material by both investigators, as well as briefing between analysis of each program to ensure coding was consistent and interpretations were well anchored. Finally, dependability should be enhanced by the detailed methods outlined in this paper. An identified limitation, however, could be the analysis of text only, which excluded how information is presented and other forms of communication, such as illustrations or videos. It should also be noted that the use of social media was not explored in this study and this form of media may be important for recruitment of newer student generations.

\section{Conclusion}

Pharmacy programs must pay attention to how they position the profession in their recruitment material targeted to prospective students. Although positioning themes appear to be consistent across programs, the speech acts used to formulate positioning statements greatly vary. The findings of this study support calls for future research into the preferences of prospective students for positioning speech acts and relatability to online recruitment material.

\section{Funding}

This research did not receive any specific grant from funding agencies in the public, commercial, or not-for-profit sectors.

\section{Declaration of competing interest}

None.

\section{Acknowledgements}

The authors would like to acknowledge Professor Carlo Marra for providing feedback on an early draft of this manuscript.

\section{Appendix A. Supplementary data}

Supplementary data to this article can be found online at https:// doi.org/10.1016/j.sapharm.2020.02.019.

\section{References}

1. Holdford DA, Sratton TP. A marketing plan for recruiting students into pharmacy school-based graduate programs. A report. Am J Pharmaceut Educ. 2000;64 41S-7S. 2. White C, Louis B, Persky A, et al. Institutional strategies to achieve diversity and 
inclusion in pharmacy education. Am J Pharmaceut Educ. 2013;77:97.

3. Cain J, Romanelli F, Smith KM. Academic entitlement in pharmacy education. Am J Pharmaceut Educ. 2012;76:189.

4. Firmin MW, Bouchard V, Flexman J, Anderson Jr DC. A qualitative analysis of students' perceptions of pursuing pharmacy as a potential vocation. Qual Rep. 2014;19:1-12.

5. Anderson JDC, Sheffield MC, Hill AM, Cobb HH. Influences on pharmacy students' decision to pursue a doctor of pharmacy degree. Am J Pharmaceut Educ. 2008;72:1-6.

6. Maringe F. University and course choice: implications for positioning, recruitment and marketing. Int J Educ Manag. 2006;20:466-479.

7. Davies B, Harre R. Positioning: the discursive production of selves. J Theor Soc Behav 2007;20:43-63.

8. Burr V. Social Constructivism. second ed. New York, NY: Routledge; 2003.

9. Hughes CA, Breault RR, Hicks D, Schindel TJ. Positioning pharmacists' roles in primary health care: a discourse analysis of the compensation plan in Alberta, Canada BMC Health Serv Res. 2017;17:770.

10. Hawthorne N, Anderson C. The global pharmacy workforce: a systematic review of the literature. Hum Resour Health. 2009;7:48

11. Harre R, van Langenhove L. Positioning Theory: Moral Contexts of Intentional Action Oxford, UK: Blackwell; 1999.

12. Davies B, Harre R. Positioning the discursive production of selves. $J$ Theor Soc Behav. 1990;20:43-63.

13. Baxter J. Positioning language and identity. In: Preece S, ed. The Routledge Handbook of Language and Identity. Abingdon, UK: Routledge; 2016:34-49.

14. Braun V, Clarke V. Using thematic analysis in psychology. Qual Res Psychol. 2006;3:77-101

15. Schindel TJ, Given LM. The pharmacist as prescriber: a discourse analysis of newspaper media in Canada. Res Soc Adm Pharm. 2013;9:384-395.

16. O'Brien BC, Harris IB, Beckman TJ, Reed DA, Cook DA. Standards for reporting qualitative research: a synthesis of recommendations. Acad Med. 2014;89:1-7.

17. QS Quacquarelli Symonds Limited. QS world university rankings by subject. https:// www.topuniversities.com/subject-rankings/2019; 2019 Accessed 11.11.18.

18. University of Otago. School of pharmacy. https://www.otago.ac.nz/pharmacy/ index.html; 2019 Accessed 03.03.19.

19. University of Auckland. School of pharmacy. https://www.auckland.ac.nz/en/ fmhs/about-the-faculty/sop.html; 2019 Accessed 03.03.19.

20. University of Sydney. Bachelor of pharmacy. https://sydney.edu.au/courses/ courses/uc/bachelor-of-pharmacy.html; 2019 Accessed 03.03.19.

21. Monash University. Faculty of pharmacy and pharmaceutical sciences. https:// www.monash.edu/pharm; 2019 Accessed 03.03.19.

22. University College London. School of pharmacy. https://www.ucl.ac.uk/pharmacy/; 2019 Accessed 03.03.19.

23. University of Nottingham. School of pharmacy. https://www.nottingham.ac.uk/ pharmacy/; 2019 Accessed 03.03.19.

24. University of Toronto. Leslie dan faculty of pharmacy. https://www.pharmacy. utoronto.ca; 2019 Accessed 03.03.19.

25. University of British Columbia. Faculty of pharmaceutical sciences. https:// pharmsci.ubc.ca; 2019 Accessed 03.03.19.

26. University of California at San Francisco. School of pharmacy. https://pharmacy. ucsf.edu; 2019 Accessed 03.03.19.

27. University of Michigan. College of pharmacy. https://pharmacy.umich.edu; 2019 Accessed 03.03.19.

28. Ayres L, Kavanaugh K, Knafl KA. Within-case and across-case approaches to qualitative data analysis. Qual Health Res. 2003;13:871-883.

29. Plewa C, Ho J, Conduit J, Karpen IO. Reputation in higher education: a fuzzy set analysis of resource configurations. J Business Res. 2016:69:3087-3095.

30. Lantos GP. Marketing to millennials: reach the largest and most influential generation of consumers ever. J Consum Market. 2014;31:401-403 